Rafael Mandressi, La mirada del anatomista. Disecciones e invención del cuerpo en Occidente, México, UIA, 2012, 327 pp. (Colección El Oficio de la Historia).

$\mathrm{E}$ n octubre de 2013 se presentó en Universum, museo de ciencias perteneciente a la UNAM, la exposición de Gunther von Hagen denominada Body Worlds, en la cual se mostraron cuerpos plastinados en diversas posiciones, mismos que permiten admirar la manera en que trabajan los músculos, las articulaciones, los huesos y los nervios. Este tipo de exhibiciones no sólo revela la admiración que sentimos por la mecánica del cuerpo humano, sino que también muestra que un cuerpo descarnado, por más artificial que pueda ser, no causa sensaciones de repudio y de asco, así como tampoco genera controversias de tipo religioso o ético. La fascinación por el cuerpo humano es un producto cultural de la modernidad, tal como lo advierte Rafael Mandressi en La mirada del anatomista, libro que resulta sugerente por la forma en que el autor reconstruye el saber anatómico que se configuró en torno a lo que denomina la "mirada del anatomista", misma que convierte el cuerpo en un objeto de conocimiento. Lo paradójico del asunto es que el anatomista busca explicar lo viviente en los cuerpos inertes. A fin de entender lo que denomina la "civilización de la anatomía", el autor plantea un recorrido histórico que comienza en 1270 y termina en los primeros decenios del siglo XIX, cinco siglos en los que la mirada anatómica elaboró, de manera paulatina, una arquitectura de lo corporal que se manifestó en un cambio cultural derivado de una colonización de la carne y del imaginario.

¿Cómo se construyó la mirada del anatomista? ¿Por qué la anatomía se constituyó en un dispositivo de conocimiento? ¿Cómo definir esa civi-

\title{
(ㅇ)(1) $\$$
}


lización de la anatomía? Estas preguntas son centrales en la exposición de Mandressi, quien busca entender cómo es que la apertura e inspección sistemática del cuerpo se convirtió en un medio privilegiado para conocerlo, situación que resulta de particular importancia si se tiene en cuenta que entre el siglo III a. C. y el siglo XIV no se realizaron disecciones. La ausencia de este procedimiento en un periodo tan largo de la historia fue consecuencia de varios factores: la influencia del cristianismo sobre las prácticas corporales y las representaciones del cuerpo, la carencia de técnicas adecuadas para hacerlo, las prohibiciones institucionales, la falta de un conocimiento apropiado como consecuencia del declive de la cirugía en la Alta Edad Media y la creencia de que no eran necesarias para perfeccionar el saber sobre el cuerpo. Si bien es cierto que las creencias religiosas tuvieron un papel determinante, pues se especulaba tanto en los medios populares como en los círculos teológicos que para lograr la resurrección se requería de la integridad del cuerpo, no se puede pasar por alto que antes del siglo XIV no existió ningún tipo de estimulo al estudio de la anatomía. De hecho, a algunos clérigos se les prohibió el estudio de la medicina y la cirugía. La proscripción fue consecuencia, entre otras cosas, del "tabú de la sangre", que impedía a los cirujanos realizar sus actividades en función de que se les consideraba "turbios", "iletrados" y "despreciables". Así, por ejemplo, se consideraba deshonroso que un maestro en medicina operara manualmente, motivo por el que no debe sorprender que la cirugía fuese considerada una de las "artes mecánicas".

Es de interés destacar que en las clases de cirugía estaban presentes tres personas: el magister, el demonstrator y el prosector. A cada uno se le identificaba con un diferente instrumento: el primero tenía un libro, el segundo una vara y el último un cuchillo. Ahora bien, la aparición de las disecciones resultaba fundamental para satisfacer las nuevas exigencias de conocimiento del cuerpo humano, lo cual es consecuencia del lugar que se le otorgó a la anatomía, debido, en buena medida, a la traducción de textos de autores árabes, quienes a su vez reproducían el pensamiento griego, lo que generaría una reconfiguración de la medicina medieval. Así, la anatomía adquirió un nuevo estatuto derivado del hecho de que se percibía su importancia para la práctica quirúrgica, caso contrario de las disecciones, que lograrían relevancia cuando se les entendió como un procedimiento de investigación y de enseñanza. En este sentido, la emergencia de la disección no fue fruto de una curiosidad anatómica, sino la valorización de la experiencia como

\section{()(1) $(9$}


principio de acceso a la realidad del mundo, de tal manera que la vista y el tacto se convirtieron en elementos centrales para refutar o rectificar las ideas de Galeno, como lo hicieron, entre otros, Andrés Vesalio, Charles Estienn y William Harvey. En este contexto, las facultades de medicina destinaron un lugar especial, el teatro, para realizar las disecciones y, sobre todo, para poder observarlas. La práctica de las disecciones produciría una interesante relación entre artistas y anatomistas, pues el saber anatómico se incorporó como un componente esencial de la figuración de las formas del cuerpo. La participación de los artistas en el establecimiento de la iconografía anatómica se produjo sobre la base de que la ilustración cumplía un papel esencial en el dispositivo de conocimiento organizado en torno a la percepción visual.

Como los pintores y los anatomistas compartían los mismos valores en cuanto a la experiencia sensorial, se generó una mutua influencia en la que unos retomaban el conocimiento y otros aportaban una dimensión estética, con lo que la vista y el tacto se consideraron indispensables en la ciencia del cuerpo. Este no fue el único mecanismo que los anatomistas utilizaron para difundir sus conocimientos, pues también recurrieron al saber libresco que proporcionó el marco de inteligibilidad que permitiría modelar una mirada y construir un cuerpo. La organización del relato anatómico se hará en función de la forma en que se presentaban las partes y las maneras de dividir el cuerpo, pues no todos los espacios corporales se definían y ordenaban por medio de la disección. De hecho, existían supuestos anatomofisiológicos y un criterio jerárquico que conducía de abajo hacia arriba y de lo imperfecto a lo noble. Así, se hablaba de tres cavidades en las que se dividía el cuerpo: venter inferior, venter medius y venter superior, división que se modificaría con el paso del tiempo pues, en el siglo XVI se consideraban cuatro partes del cuerpo: cabeza, tórax, vientre y extremidades. Se generó, en este sentido, una reconstitución conceptual del cuerpo que tenía un paralelismo con la arquitectura, de tal forma que el cuerpo, como soporte y estructura, se describía de acuerdo con un orden de composición pensado como secuencia constructiva. El problema de las proporciones, centro de preocupación de los artistas, ocupó un lugar central en los escritos de los anatomistas y proporciona algunos horizontes epistemológicos del saber anatómico, pues se instituyó una norma que buscaba dar cuenta de la realidad morfológica del cuerpo, aunque esta no se materializara en su perfección.

\section{()(1) $(9$}


En este sentido, se decía que el cuerpo perfecto debía estar dotado de simetría, en tanto que su desviación ponía de manifiesto lo "monstruoso", las infracciones del canon y la variabilidad de los cuerpos. Así, la belleza y la buena constitución del cuerpo se integrarían en un mismo imaginario. El que la nueva ciencia anatómica uniera el pensamiento médico con las artes visuales evidenciaba una vasta red de prácticas, discursos y conocimientos, mismos que pasaban de la mesa de disección a las diversas áreas del conocimiento, lo cual suponía una manera específica de percibir y de aprehender la naturaleza, la organización y el funcionamiento del cuerpo humano. Madressi indica que una de las características de la anatomía es que se convirtió en portadora de un proyecto de fragmentación, lo que significó, en última instancia, que la comprensión del cuerpo no se realizaba en términos unitarios. Se buscaba diseccionar hasta las piezas más pequeñas del cuerpo para tratar de comprender su funcionamiento. Con la aparición del microscopio se llevaría la disección hasta lo más diminuto, lo que significó una redefinición de la parte que, al ser entendida como pieza, daba cuenta de la vinculación del cuerpo con la maquinaria, por lo que comenzaron a utilizarse analogías relativas al funcionamiento de las máquinas y la mecanización del cuerpo. A la par de esta concepción mecanicista aparecería otra que vinculaba el saber anatómico con el astral, la cual buscaba vincular el cuerpo con el cosmos, pues se pensaba que este representaba una extensión de las fuerzas, las formas y los elementos del universo. El entrelazamiento del saber anatómico y la astrología seguiría vigente hasta las primeras décadas del siglo XVII. Estas dos concepciones reproducían una tradición antigua que se fundaba en la idea de que existía una conexión entre el hombre y el mundo.

Si bien es cierto que las disecciones se convirtieron en un asunto más frecuente, ello no significó que se hubiera eliminado el misterio, el pavor y la fascinación que representaba el hurgar entre tejidos inertes. La tarea del anatomista se tornaba penosa en cuanto debía manipular la carne y hundir su mano en ella, situación que, en buena medida, no sólo era repulsivo sino que también se enfrentaba el peligro de una infección. Para lograr una buena disección, se requería de instrumentos apropiados y de la elección de un buen cuerpo. Sin embargo, la existencia de normativas respecto a quiénes podían diseccionar y del número de cuerpos de que podían disponer, provocó que los anatomistas recurrieran a procedimientos ilícitos para obtener los cadáveres que requerían, práctica que fue frecuente en París durante las primeras

\section{()(1) $(9$}


décadas del siglo XVIII y que se explica por el hecho de que esta ciudad se había convertido en uno de los principales centros de la enseñanza anatómica y quirúrgica. De hecho, los estudiantes tenían la posibilidad de practicar disecciones y no sólo de asistir a las demostraciones de los profesores. Las prácticas ilícitas de los anatomistas contribuirían a crear un imaginario que los mostraba como hombres crueles, que despedazaban los cuerpos con "manos inexpertas", además de que trabajaban en "malas condiciones" y con una absoluta falta de higiene, lo que podía provocar un "peligro mortal". Así, la figura del anatomista se consideraba controversial y se convirtió en objeto de atención de numerosos escritores, entre los que destacaba Diderot, quien escribió para la Encyclopedie, el artículo "Anatomía", en el cual proponía la vivisección en el cuerpo de los condenados a muerte, propuesta que se integraría al "inventario de la crueldad anatómica".

Mandressi advierte que no existen pruebas de que se hubieran realizado vivisecciones, pero este tipo de propuestas demostraba el tipo de acciones que se buscaba llevar a cabo en el afán de obtener cierto tipo de conocimiento. Es por esta razón que se planteaba la teoría del hombre máquina que, en cierta forma, justificaba la disección humana en función de que se requería conocer el funcionamiento del cuerpo para hacerlo trabajar. Se creía que el conocimiento de los anatomistas se podría volver realidad en los autómatas, lo cual significaba que la acción de la naturaleza podía reproducirse a través de un artificio. De hecho, los mecánicos buscaron fabricar un autómata que realizara las mismas operaciones que un hombre vivo, tales como la respiración, la circulación, la digestión y la secreción. El recorrido histórico planteado por el autor muestra que el conocimiento anatómico no pertenece sólo a la historia de la medicina, sino que también es una historia cultural que evidencia los diferentes imaginarios que se formaron en torno al cuerpo. La importancia alcanzada por la anatomía se apreciaba en las funciones públicas pagadas para observar las disecciones, en su inclusión como parte de la educación de la nobleza y, sobre todo, en su capacidad de explicación, pues permitía dar cuenta de la parte y del todo. Sin embargo, la difusión del conocimiento anatómico alcanzó mayor relevancia merced a las imágenes producidas por los artistas, aunque lo interesante del asunto es que en la ilustración anatómica predominara lo estético sobre lo científico, lo cual no significaba que existiera un divorcio entre las artes visuales y el conocimiento anatómico.

\section{()(1) $(9$}


El fascinante libro de Mandressi evidencia que la historia de la anatomía es una historia de la conquista del cuerpo, pero también de su invención a partir de las disecciones, que se constituyeron en un dispositivo heurístico históricamente construido y sustentado en estrategias epistemológicas particulares, las cuales contribuyeron a generar una mirada específica sobre el cuerpo. No me cabe la menor duda de que este texto será de gran utilidad para los historiadores y los médicos. Para los primeros por el notable manejo de fuentes y de herramientas teórico-metodológicas que sustentan sus interpretaciones de este fenómeno cultural, mientras que para los segundos debe constituir una invitación a comprender, desde una perspectiva analítica distinta, las prácticas anatómicas del pasado y la manera en la que este conocimiento ha sufrido transformaciones que no sólo competen al ámbito científico.

Rogelio Jiménez Marce IICsyн-Benemérita Universidad Autónoma de Puebla, México rojimarc@yahoo.com.mx 